\title{
Discovery of riociguat (BAY 63-252I): a potent, oral stimulator of soluble guanylate cyclase for the treatment of pulmonary hypertension
}

Joachim Mittendorf1 ${ }^{1}$, Stefan Weigand ${ }^{1,4}$, Cristina Alonso-Alija1, Erwin Bischoff2, Achim Feurer1,5, Michael Gerisch ${ }^{3}$, Armin Kern ${ }^{3}$, Andreas Knorr ${ }^{2}$, Dieter Lang ${ }^{3}$, Klaus Muenter ${ }^{2}$, Martin Radtke, Hartmut Schirok ${ }^{1}$, Karl-Heinz Schlemmer ${ }^{3}$, Elke Stahl ${ }^{3}$, Alexander Straub ${ }^{1}$, Frank Wunder ${ }^{2}$ and Johannes-Peter Stasch*2

\author{
Address: ${ }^{1}$ Bayer Schering Pharma AG, Medicinal Chemistry Wuppertal, Pharma Research Center, 42096 Wuppertal, Germany, ${ }^{2}$ Bayer Schering \\ Pharma AG, Cardiovascular Research, Pharma Research Center, 42096 Wuppertal, Germany, ${ }^{3}$ Bayer Schering Pharma AG, DMPK, Pharma \\ Research Center, 42096 Wuppertal, Germany, ${ }^{4}$ Roche, Nonnenwald 2, 82377 Penzberg, Germany and ${ }^{5}$ Santhera Pharmaceuticals Ltd., \\ Hammerstrasse 47, 4410 Liestal, Switzerland \\ Email: Johannes-Peter Stasch* - joachim.mittendorf@bayerhealthcare.com \\ * Corresponding author
}

from 4th International Conference of cGMP Generators, Effectors and Therapeutic Implications Regensburg, Germany. 19-21 June 2009

Published: II August 2009

BMC Pharmacology 2009, 9(Suppl I):P52 doi:I0.1186/I47I-22 I0-9-SI-P52

This abstract is available from: http://www.biomedcentral.com/I47I-22 I0/9/SI/P52

(c) 2009 Mittendorf et al; licensee BioMed Central Ltd.

Soluble guanylate cyclase (sGC) is a key signal-transduction enzyme activated by nitric oxide (NO). Impairments of the NO-sGC signaling pathway have been implicated in the pathogenesis of cardiovascular and other diseases. Direct stimulation of sGC represents a promising therapeutic strategy particularly for the treatment of pulmonary hypertension (PH), a disabling disease associated with a poor prognosis. Previous sGC stimulators such as the pyrazolopyridines BAY 41-2272 and BAY41-8543 demonstrated beneficial effects in experimental models of $\mathrm{PH}$, but were associated with unfavorable drug metabolism and pharmacokinetic (DMPK) properties. Herein we disclose an extended SAR exploration of this compound class to address these issues. Our efforts led to the identification of the potent sGC stimulator riociguat, which exhibits an improved DMPK profile and exerts strong effects on pulmonary hemodynamics and exercise capacity in patients with PH. Riociguat (BAY 63-2521) is currently being investigated in phase III clinical trials for the oral treatment of PH. 